\title{
Variations of ovarian position in Fasciola hepatica species found in cattle in Puerto Rico'
}

\author{
Pedro Bendezú, Anne D. Frame and Regina Bendezú ${ }^{2}$
}

\begin{abstract}
Examination of Fasciola hepatica (Linnaeus, 1758) worms taken from infected bovine livers in Puerto rico revealed the presence of flukes whose ovarian positions vary. In the majority of the flukes observed $(88 \%)$, the ovary was dextral to the centrally located ootype. In the second group of flukes $(8 \%)$, the ovary was sinistral to the ootype, and a still smaller group $(4 \%)$ showed two ovarian branches emerging from a single oviduct trunk anterior to the ootype. This study revealed that in a population of 2,100 F. hepatica flukes the dextral ovarian position was predominant. The sinistral and bifurcated ovarian positions were in the minority. Additional studies are needed to determine the genetic stability of the variations.
\end{abstract}

\section{RESUMEN}

Variaciones de la posición del ovario en la fasciola hepatica encontradas en el ganado vacuno de Puerto Rico

Examinando la posición del ovario de 2,100 especímenes de Fasciola hepatica se observó que el $88 \%$ de los parásitos presentaron las ramificaciones del ovario en posición dextral, el $8 \%$ sinestral y el $4 \%$ con ramificaciones en ambos lados. El punto de referencia se relacionó con el ootipo, localizado en el tercio anterior y central del parásito, visto ventralmente. Se requieren estudios genéticos adicionales para establecer su estabilidad o variación genética.

\section{INTRODUCTION}

Variations in Fasciola species have been observed in the past. The variant forms have either been given specific identity or simply considered strains. The variations have ranged from differences in egg size (3, 4) to morphological differences in the adult flukes $(9,12)$.

Some forms of $F$. hepatica (Linnaeus, 1758) were considered distinct species by Sinitsin (10), who studied the life histories of some American flukes and concluded that there were two species of Fasciola in sheep and cattle in the United States of America, $F$. californica and $F$. halli. Price (8) considered the flukes in the Gulf Coast region of the United States to be hybrids of $F$. hepatica and $F$. gigantica, (Cobbold, 1856). Malek (6) concurred that various strains had developed in different geographic locations. Members of the genus Fasciola have such similar life cycles that they are difficult to separate as distinct species (7).

'Manuscript submitted to Editorial Board 27 June 1990.

Department of Biology, Division of Sciences and Technology, Inter American University of Puerto Rico. 


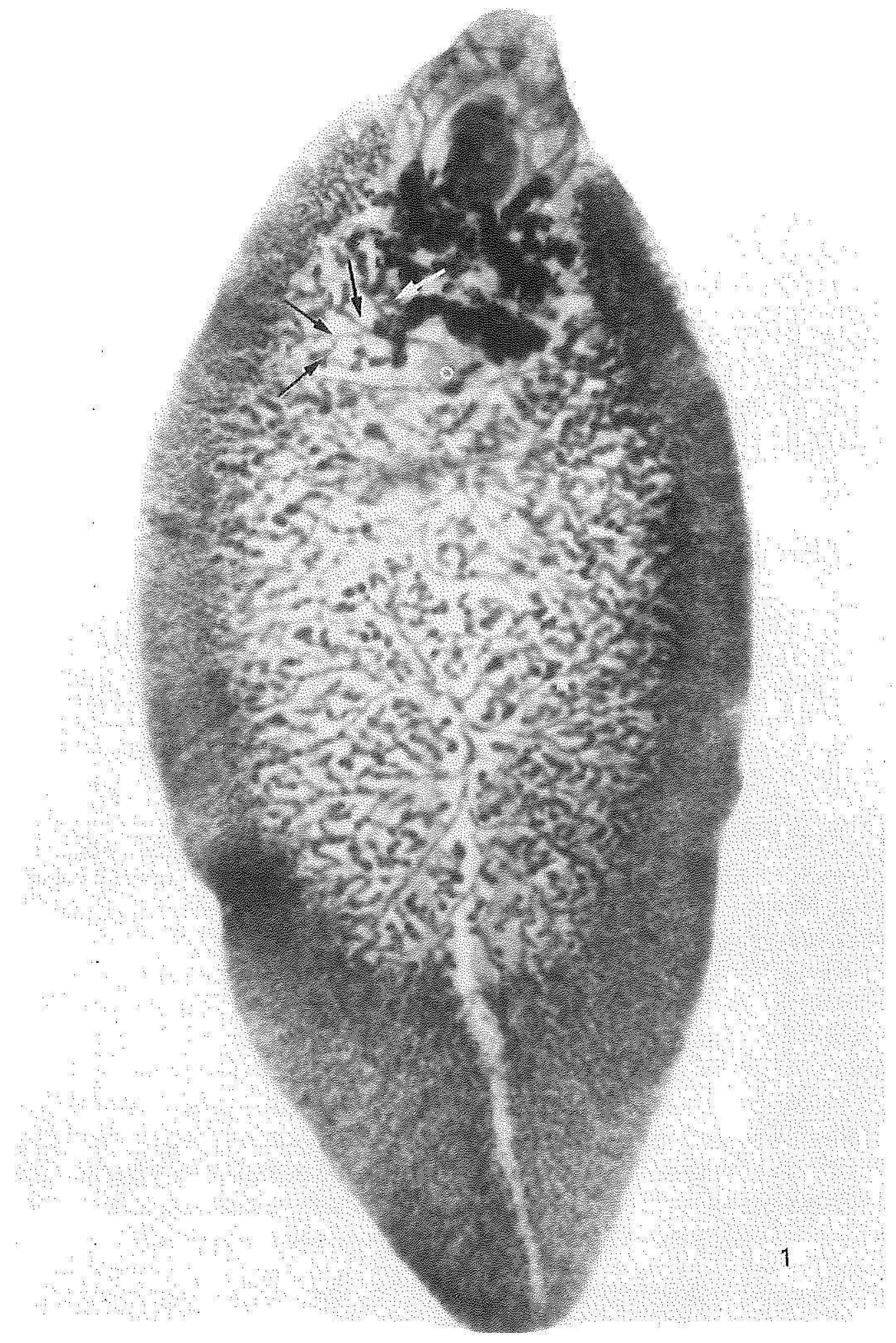

Fig. 1.-Fluke showing ovary positioned dextral (arrow) to the centrally located ootype (o), (photographed ventral side facing viewer). 
$F$. hepatica is known to have an ovarian position dextral to the ootype of the fluke and $F$. gigantica has a sinistral oriented ovary (6). $F$. hepatica and $F$. gigantica are considered the principal species causing fascioliasis in ruminants and other mammalian hosts $(2,5,6,11)$.

In Puerto Rico, de León (1) considers $F$. hepatica the valid species causing liver fluke infection. $F$. gigantica has not been reported on the island (2).

\section{MATERIALS AND METHODS}

Sixty livers infected with $F$. hepatica were randomly selected from four different abattoirs in Puerto Rico, specifically in Cubuy, Manatí, Corozal and Guaynabo; approximately 15 livers were taken from each. The 2,100 flukes collected from the infected livers were washed in physiological saline solution for 5 hours. Subsequently, these were fixed in $10 \%$ formalin solution for 12 hours at room temperature and washed under running tap water for another 12 hours. The flukes were then placed in alumine carmine for 12 hours for intense staining, after which time they were destained with acidic alcohol (HClc/60\% alcohol, 0.05:1). This step was followed by dehydration in a battery of ethanol alcohol solutions $(60,70,80,90,95$ and $100 \%)$. The samples were then placed in xylene for 30 minutes for clearing, then mounted on a slide with Canada balsam. It was at this point that the ovarian positions were visible only if viewed ventral side up with the stereoscope.

\section{RESULTS AND DISCUSSION}

Observations of the flukes revealed that the position of the ovary was the most obvious morphological feature where differences could be microscopically discerned. Differences in the ovarian positions in relation to the ootype could be seen in both juvenile and adult worms.

Most of the flukes observed (88\%) showed the ovary to be dextral to the centrally located ootype (fig. 1). This is the usual ovarian position for $F$. hepatica (6). A second group of the flukes (8\%) had the ovary sinistral to the ootype (fig. 2). A still smaller group (4\%) of the flukes had two pairs of ovaries, one on the left and another on the right side, both arising from the centrally located oviduct at the anterior end of the ootype (fig. 3).

In the initial search for flukes the livers were grouped according to visible liver damage. Of these, $14 \%$ had light lesions with inflamed bile ducts, $40.14 \%$ had bile ducts with fibrotic lesions and $45.86 \%$ had massive infections with severe fibrosis of the bile ducts and partial cirrhosis of the liver. It was in the latter group that the largest number of flukes were obtained. Flukes of all three ovarian positions were found in all three groups of livers. The effect of the ovarian position on infectivity in terms of visible liver damage could not be determined. 


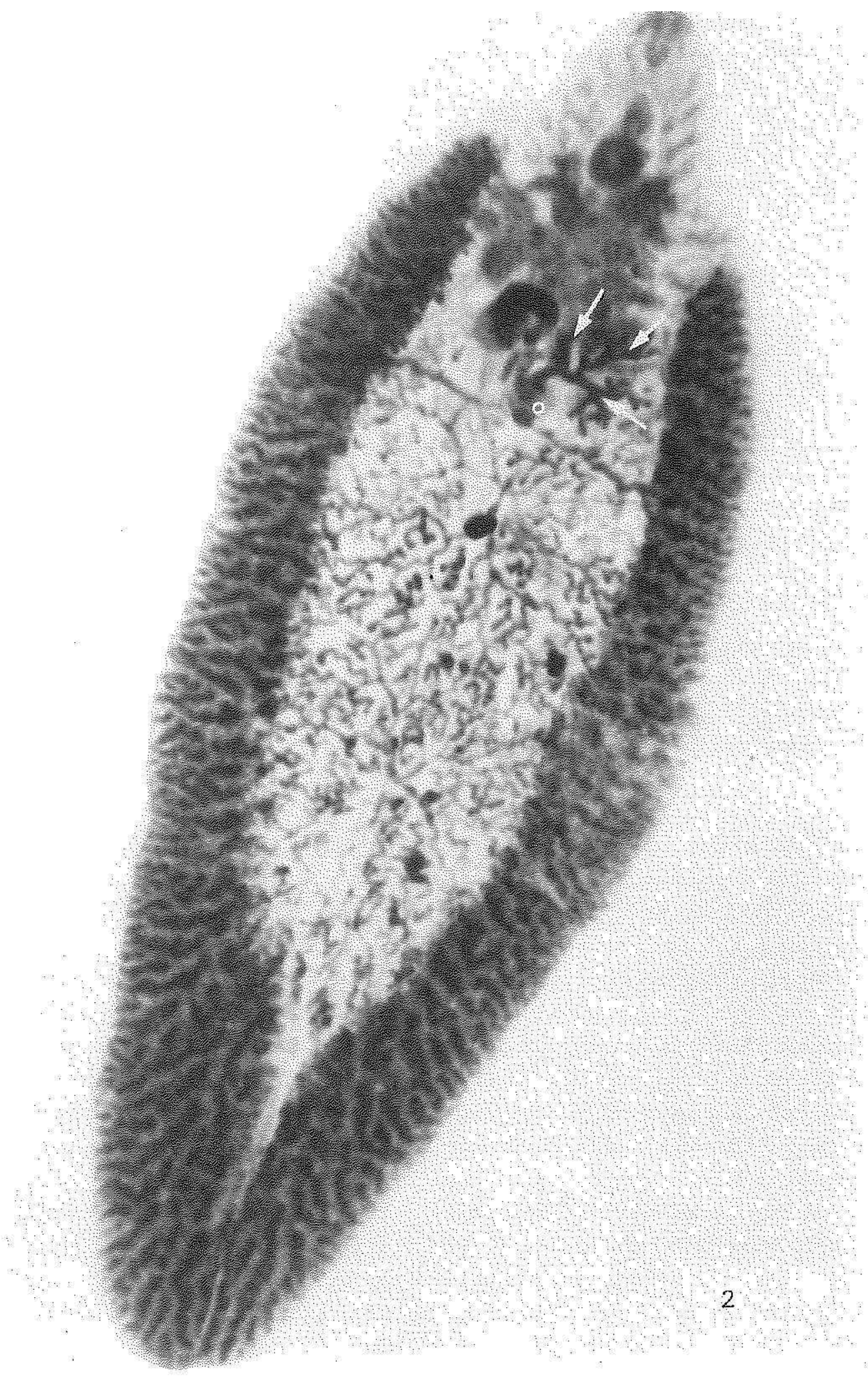

Fig. 2.-Fluke showing ovary positioned sinistral (arrow) to the centrally located ootype (o), (photographed ventral side facing viewer). 
J. Agric. Univ. P.R. vol. 75, NO. 1, JANUARY, 1991

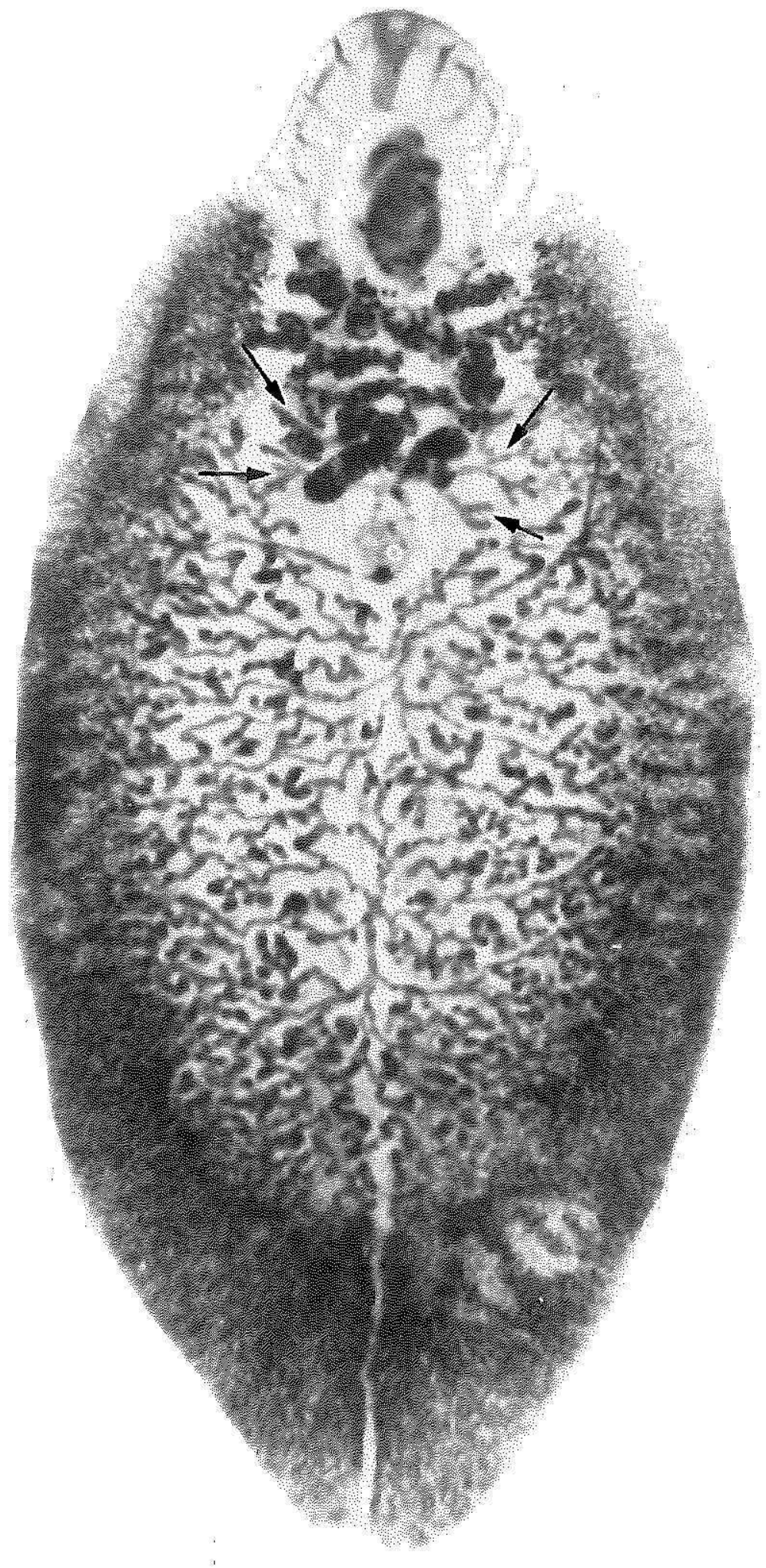

Fig. 3.-Fluke showing ovary positioned on both sides (arrows) emerging from the centrally located oviduct at the ootype (o), (photographed ventral side facing viewer). 
Variants of $F$. hepatica reported here are repeatedly found occurring in cattle in Puerto Rico. The persistence of the ovarian variations seen in $F$. hepatica flukes here could be significant. Additional studies are needed to determine whether the flukes with the different ovarian positions are hybrids of $F$. hepatica or distinct species present in a mixed infection.

\section{LITERATURE CITED}

1. De León, D., L. S. Ritchie and J. Chiriboga, 1972. Fascioliasis in dairy cattle in Río Plata basin of the Dorado Area, P. R. J. Agric. Univ. P. R. 56 (1): 82-92.

2. 1990. Unpublished data. Personal communication.

3. Jansen, J., 1972. New cases of Fasciola hepatica with large eggs. Int. J. Parasitol, 2: 281 .

4. - - and H. J. Over, 1963. On a remarkable strain of Fasciola hepatica in the Netherlands. Tijdschr. Diergeneeskd., 88: 770.

5. Kendall, S. B., and J. W. Partfitt, 1959. Studies on the susceptibility of some species of Lymnaea to infection with Fasciola gigantica and Fasciola hepatica. Ann. Trop. Med. Parasit., 53: 220-27.

6. Malek. E. A., 1980. Snail transmitted parasitic diseases. CRC Press Vol. 2: 136-70.

7. Pantelouris, E. M., 1965. The common liver fluke Fasciola hepatica. L. Pergamon Press, Oxford.

8. Price, E. W,. 1953. The fluke situation in American ruminants. J. Parasitol., 39: $119-34$.

9. Sarwar, M. M., 1957. Fasciola indica. Varma, a synonym of $F$ asciola gigantica (Cobbold), Biologia, Lahore, Pakistan 3: 168-75.

10. Sinitzin, D. F., 1933. Studien über die Phylogenie der Trematoden. The life histories of some American liver flukes. Parasitenk., 6 (170):91.

11. Soulsby, E. J. L., 1977. Textbook of Veterinary Parasitology. Blackwell Scientific Publications, Oxford.

12. Varma, A. K., 1953. On Fasciola indica N. sp. with some observations on $F$. hepatica and $F$. gigantica. J. Helminthol., 27: 185-98. 